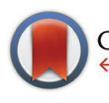

CrossMark $\leftarrow$ click for updates

Cite this: Dalton Trans., 2014, 43 16666

Received 26th June 2014, Accepted 18th September 2014 DOI: 10.1039/c4dt01930j www.rsc.org/dalton

\section{Atomic layer deposition of sodium and potassium oxides: evaluation of precursors and deposition of thin films $\dagger$}

\author{
E. Østreng, ${ }^{a, b}$ H. H. Sønsteby, ${ }^{{ }^{a}}{ }^{\text {S }}$. Øien, ${ }^{a}$ O. Nilsen ${ }^{a}$ and H. Fjellvåg ${ }^{a}$
}

Thin films of sodium and potassium oxides have for the first time been deposited using atomic layer deposition. Sodium and potassium complexes of tert-butanol, trimethylsilanol and hexamethyldisilazide have been evaluated as precursors by characterising their thermal properties as well as tested in applications for thin film depositions. Out of these, sodium and potassium tert-butoxide and sodium trimethylsilanolate and hexamethyldisilazide were further tested as precursors together with the $\operatorname{Al}\left(\mathrm{CH}_{3}\right)_{3}+$ $\mathrm{H}_{2} \mathrm{O} / \mathrm{O}_{3}$ process to form aluminates and together with ozone to form silicates. Sodium and potassium tert-butoxide and sodium trimethylsilanolate showed self-limiting growth and proved useable at deposition temperatures from 225 to 375 or $300{ }^{\circ} \mathrm{C}$, respectively. The crystal structures of $\mathrm{NaO}{ }^{t} \mathrm{Bu}$ and $\mathrm{KO}^{t} \mathrm{Bu}$ were determined by single crystal diffraction revealing hexamer- and tetramer structures, respectively. The current work demonstrates the suitability of the ALD technique to deposit thin films containing alkaline elements even at 8 " wafer scale.

\section{Introduction}

Atomic layer deposition (ALD) is a versatile thin film deposition technique shown to be useable for most elements in the periodic table. ${ }^{1}$ However, deposition of compounds with alkali metals has so far been limited to lithium. Deposition of lithium containing thin films was demonstrated in 2009, and was recently reviewed as a result of a surge in interest of lithium compounds. ${ }^{2-12}$ Despite the recent interest in lithium based ALD-processes, no other alkali metal processes have been reported. Research on lithium based processes has mainly been driven by its potential impact in solid state lithium ion batteries. Likewise, sodium and potassium are constituents in numerous alternative functional materials with high technological potential, such as thermoelectrics (e.g. $\mathrm{Na}_{x} \mathrm{CoO}_{2}$ ), superconductors (e.g. $\mathrm{Na}_{x} \mathrm{CoO}_{2} \cdot \mathrm{H}_{2} \mathrm{O}$ ), dielectrics (e.g. $\left.\mathrm{NaNbO}_{3}\right)$ and piezoelectrics $\left(\mathrm{K}_{1-x} \mathrm{Na}_{x} \mathrm{NbO}_{3}\right) .{ }^{13-17}$ Recently, sodium has also received attention in less expensive sodium ion batteries as alternatives to lithium ion batteries. ${ }^{18,19}$ Alkali metal compounds have previously been deposited as thin films by techniques such as pulsed layer deposition, chemical

${ }^{a}$ Centre for Materials Science and Nanotechnology, Department of Chemistry, University of Oslo, P.O. Box 1033 Blindern, N-0135 Oslo, Norway. E-mail: henrik.sonsteby@kjemi.uio.no

${ }^{b}$ Currently working at Picosun Oy, Tietotie 3, 02150 Espoo, Finland

$\dagger$ Electronic supplementary information (ESI) available. CCDC 1017545. For ESI and crystallographic data in CIF or other electronic format see DOI: 10.1039/ c4dt01930j vapour deposition (CVD) and chemical solution deposition, in addition to the present examples of using ALD. ${ }^{20-25}$ The reported span in precursors for deposition of sodium and potassium oxides is somewhat limited. For CVD, $\beta$-diketonates are common, while solution based methods often use alkali metal alkoxides or acetates. ${ }^{16,21,23-30}$

This work is focused on a selection of three ligand systems for sodium and potassium precursors which are assumed to react with both water and ozone in an ALD-process. The potential precursors are the trimethyl silanolates (TMSO), tert-butoxides $\left(\mathrm{O}^{t} \mathrm{Bu}\right)$, and the hexamethyldisilazides (HMDS, also known as bis (trimethylsilyl)amide) of sodium and potassium, Fig. 1. The HMDS- and $\mathrm{O}^{t} \mathrm{Bu}$-compounds were selected due to the success of their corresponding lithium analogues, which reacts with both water and ozone, and the TMSO compounds for their assumed similarity to $\mathrm{O}^{t} \mathrm{Bu} \cdot{ }^{3-5,12}$ The structures and properties of the alkali-HMDS-compounds are rather varied, where $\mathrm{Li}^{-}$and NaHMDS are reported to be covalent com-

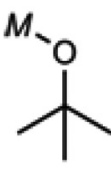

$\mathrm{O}^{1} \mathrm{Bu}$

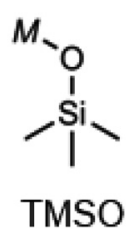

TMSO

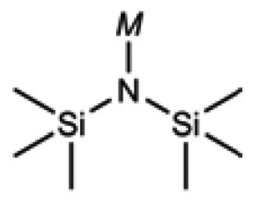

HMDS
Fig. 1 Schematic drawings of the ligands used in this work, tert-butoxide $\left(\mathrm{O}^{t} \mathrm{Bu}\right)$, trimethyl silanolate (TMSO) and hexamethyldisilazide (HMDS), respectively. 
pounds and KHMDS is reported as ionic. ${ }^{31}$ LiHMDS is trimeric in the solid state and dimeric in gas phase while NaHMDS is polymeric in the solid state and monomeric in gas phase. ${ }^{32-34}$ KHMDS is reported to be a dimer in the solid state, but to our knowledge no reports have been made regarding its gas phase structure. $^{35}$

The sodium and potassium tert-butoxides and the sodium silanolate form cages in both the solid and gas phase, where potassium forms cages with four metal atoms per cage and sodium is reported here to form cages with six or nine metal atoms per cage. ${ }^{36-38}$ The $\beta$-diketonates such as $\mathrm{Na}$ (thd) and $\mathrm{K}$ (thd) (thd $=$ 2,2,6,6-tetramethyl-3,5-heptadionate) could also be suitable precursors, as this precursor family has proven successful in many ALD-processes, including deposition of lithium containing compounds. ${ }^{1,3}$ However, these have not been studied in this work.

The current work builds on the present knowledge in deposition of lithium based compounds. Deposition of pure lithium oxide or lithium hydroxide has been reported to be troublesome due to absorption of water or $\mathrm{CO}_{2}$ during and after the deposition process. ${ }^{4,39}$ To avoid similar challenges, this work reports the deposition of sodium and potassium through growth of its aluminates and/or silicates. Aluminates were chosen as a model system due to the high reproducibility of the TMA- $\mathrm{H}_{2} \mathrm{O}$ - and TMA-O ${ }_{3}$-processes (TMA $\left.=\mathrm{Al}\left(\mathrm{CH}_{3}\right)_{3}\right)$. Silicates were chosen as the trimethyl silanolates and hexamethyldisilazides could potentially be used as single source precursors with ozone for both the alkali metal and silicon.

\section{Experimental}

Thin films of the sodium- and potassium compounds were deposited using a Beneq TFS-500 atomic layer deposition reactor (Beneq Oy). Selected depositions of sodium silicate were also verified using an ASM F-120 Sat reactor. The solid precursors were supplied to the TFS-500 reactor from a HS-300 hot source. All films were deposited on $\mathrm{Si}(100)$ wafers. Nitrogen was used as carrier gas, supplied from a Schmidelin-Sirrco 5 providing $>99.9995 \%\left(\mathrm{~N}_{2}+\mathrm{Ar}\right)$ before purification through a Mykrolis purifier. The chemicals used are described in Table 1. Distilled water or ozone, generated from an IN-USA AC-2025 from oxygen (99.6\% AGA) measured to supply $14 \mathrm{wt} \%$ $\mathrm{O}_{3}$, was used as oxygen source.

The deposition temperature was chosen to be $250{ }^{\circ} \mathrm{C}$ for all the experiments, unless otherwise specified. The $\mathrm{H}_{2} \mathrm{O}$ pulse

Table 1 Overview of the evaluated precursors

\begin{tabular}{llc}
\hline Chemical name & Supplier & Purity \\
\hline Sodium tert-butoxide & Aldrich & $97 \%$ \\
Sodium hexamethyldisilazide & Aldrich & $95 \%$ \\
Sodium trimethylsilanolate & Aldrich & $95 \%$ \\
Potassium tert-butoxide & Aldrich & $97 \%$ \\
Potassium hexamethyldisilazide & Aldrich & $95 \%$ \\
Potassium trimethylsilanolate & Aldrich & $95 \%$
\end{tabular}

was set to $0.25 \mathrm{~s}$ and all purge durations were chosen to be $0.75 \mathrm{~s}$, ozone was supplied with a $2 \mathrm{~s}$ pulse for the Beneq reactor and $3 \mathrm{~s}$ for the ASM reactor. The magnitudes of all these parameters are known from our previous experiments with these tools and similar chemistries to be sufficient for ALD-saturative growth. The pulsing times for the sodium or potassium precursors were investigated separately and are reported below.

Thicknesses and refractive indexes (at $\lambda=632.8 \mathrm{~nm}$ ) were extracted from ellipsometry data collected with a J. A. Woolam $\alpha$-SE spectroscopic ellipsometer in the range of 390-900 $\mathrm{nm}$. The films were assumed to be transparent and modelled to a Cauchy-function, using the CompleteEASE software package.

The cationic compositions were measured with standardless X-ray fluorescence spectroscopy using a Philips PW2400 $\mathrm{XRF}$ and analyzed using the UniQuant software package.

Thermogravimetric analysis (TGA) was performed on a Perkin Elmer Pyris TGA-7, using a $2{ }^{\circ} \mathrm{C} \min ^{-1}$ ramp rate in flowing nitrogen atmosphere.

X-ray diffraction measurements were performed on a Bruker AXS D8 Discover equipped with a LynxEye strip detector. The diffractometer has a Ge(111) focusing monochromator providing $\mathrm{CuK}_{\alpha 1}$-radiation.

Fourier transformed infrared spectroscopy (FTIR) was performed under vacuum ( $\sim 3$ mbar) using a Bruker IFS66 spectrometer in transmission mode. An uncoated Si(100)-wafer was used as background.

The crystal structures of $\mathrm{NaO}^{t} \mathrm{Bu}$ and $\mathrm{KO}^{t} \mathrm{Bu}$ were solved from single crystals collected from the precursor tube of the F-120 reactor after deposition. Crystals up to $2 \times 2 \mathrm{~mm}$ were extracted and transferred to a glove box before mounting the crystals using a cryo-loop in inert atmosphere. Data was acquired at $100 \mathrm{~K}$ using a Bruker D8 Venture diffractometer equipped with a molybdenum tube $(\lambda=0.71073 \AA)$ in the range of $2 \theta=2-40^{\circ}$, and treated with the Bruker Apex 2 software suite. Shelxle and SHELXL13 were used for editing and refinement. ${ }^{40,41}$ The $\mathrm{NaO}^{t} \mathrm{Bu}$ structure was solved using the intrinsic phasing method in SHELXL13.

\section{Results}

\section{Evaluation of precursors}

All the compounds are white, dry powders, except NaTMSO which has a slight pink tint. The evaporation characteristics and possible sublimation temperatures were determined by TGA for each compound, Fig. 2. The three sodium compounds and $\mathrm{KO}^{t} \mathrm{Bu}$ were promising enough to attempt film depositions. KTMSO and KHMDS show residual masses similar to the calculated oxide residue, and appear to lose mass in stages and was therefore found unsuitable as precursor for film deposition as the compounds decompose and do not evaporate. NaHMDS was tested for deposition of thin films using ozone or by mixing with the TMA/water process, but no reproducible results could be obtained in the initial experiments. It was therefore not explored any further. 


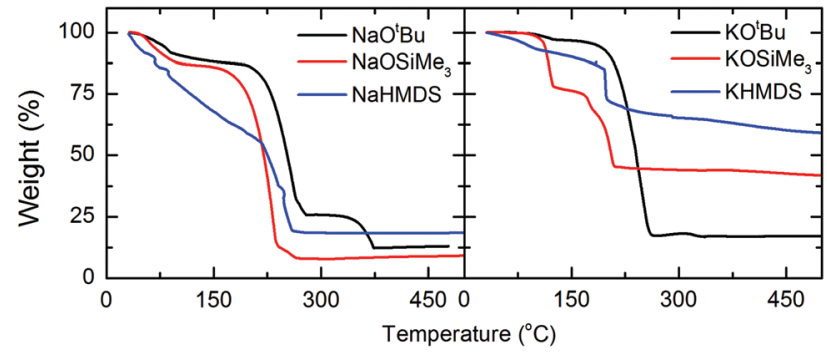

Fig. 2 Thermogravimetric analysis of chosen sodium and potassium compounds. All experiments were performed using a heating rate of $2{ }^{\circ} \mathrm{C} \mathrm{min}^{-1}$ in flowing nitrogen atmosphere.

All evaluated compounds were found to be safe to handle in air for time periods of a few minutes, but turned completely into their respective hydroxides and carbonates over the course of a couple of hours.

The crystal structure of $\mathrm{NaO}^{t} \mathrm{Bu}$ and $\mathrm{KO}^{t} \mathrm{Bu}$ was determined by single crystal diffraction, Fig. 3 (crystallographic data is reported in ESI $\dagger$ ). $\mathrm{NaO}^{t} \mathrm{Bu}$ partly dissolved when transferred to the instrument, causing increased mosaicity of the crystal and thus poor diffraction at higher angles. Nevertheless, the structure was solved and refined at $1.0 \AA$ resolution, revealing that $\mathrm{NaO}^{t} \mathrm{Bu}$ crystallizes in hexamer units with highly disordered tert-butyl groups, as shown in Fig. 3. The structure partly matches a previously reported structure consisting of similar hexamers and also nonamers. ${ }^{37}$
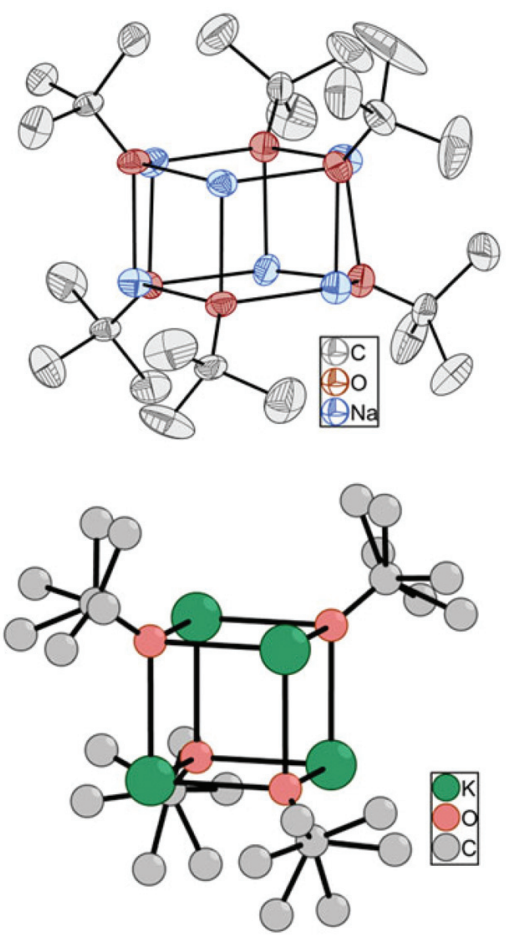

Fig. 3 Left: molecular structure of $\mathrm{NaO}^{t} \mathrm{Bu}$. Hydrogen atoms are omitted for clarity, and thermal ellipsoids are on a $50 \%$ level. Right: the previously reported structure of $\mathrm{KO}^{t} \mathrm{Bu}$ with possible configurations of the disordered methyl groups. ${ }^{38}$
The unit cell of $\mathrm{NaO}^{t} \mathrm{Bu}$ is very large, containing 5 unique hexamer units with slightly different orientation, along with 15 symmetry generated units. It was attempted to model some of the most disordered tert-butyl groups with two partially occupied conformations, but that rendered the refinement unstable. It was instead chosen to model the groups in question with large ellipsoids, applying mild isotropy restraints.

The unit cell of $\mathrm{KO}^{t} \mathrm{Bu}$ was determined from 250 reflections in the range $2 \theta=2-40^{\circ}$, and was found to match the previously reported tetramer structure. ${ }^{38}$

\section{Deposition of sodium containing thin films, the case of $\mathrm{NaO}^{t} \mathrm{Bu}$}

Deposition of sodium aluminates was done using alternating cycles of the precursor pairs $\left[\mathrm{NaO}^{t} \mathrm{Bu}+\mathrm{H}_{2} \mathrm{O}\right]$ and [TMA $+\mathrm{H}_{2} \mathrm{O}$ ]. The high sodium content region was not emphasized in the current study and thus a maximum of 50\% pulsed sodium was utilized, i.e. every other cycle $\left[\mathrm{NaO}^{t} \mathrm{Bu}+\mathrm{H}_{2} \mathrm{O}\right]$ and $[\mathrm{TMA}+$ $\mathrm{H}_{2} \mathrm{O}$ ]. The samples deposited using this 1: 1-ratio was sensitive to ambient air and developed spots and blotches over the course of a few days to a few weeks. From previous work and experience with similar lithium based processes, it is known that samples which contains high levels of lithium tends to yield uncontrolled growth due to formation of hydroxide which interferes the ALD-growth mechanism. ${ }^{12,39}$

Application of $\mathrm{NaO}^{t} \mathrm{Bu}$ as precursor was investigated using 200 super-cycles of a $1: 1$ ratio of $\left[\mathrm{NaO}^{t} \mathrm{Bu}+\mathrm{H}_{2} \mathrm{O}\right]$ : [TMA + $\mathrm{H}_{2} \mathrm{O}$ ]. The thickness and refractive index were monitored as a function of the $\mathrm{NaO}^{t} \mathrm{Bu}$ dose, which was changed by varying the source temperature or the pulse length for $\mathrm{NaO}^{t} \mathrm{Bu}$, Fig. 4 . The purge after $\mathrm{NaO}^{t} \mathrm{Bu}$ was kept at $1 \mathrm{~s}$. Surface saturation and a stable refractive index, indicating stable composition, was achieved when the precursor temperature was above $140{ }^{\circ} \mathrm{C}$ and the pulse time longer than $0.5 \mathrm{~s}$. These values were chosen for the subsequent experiments. This optimized process for

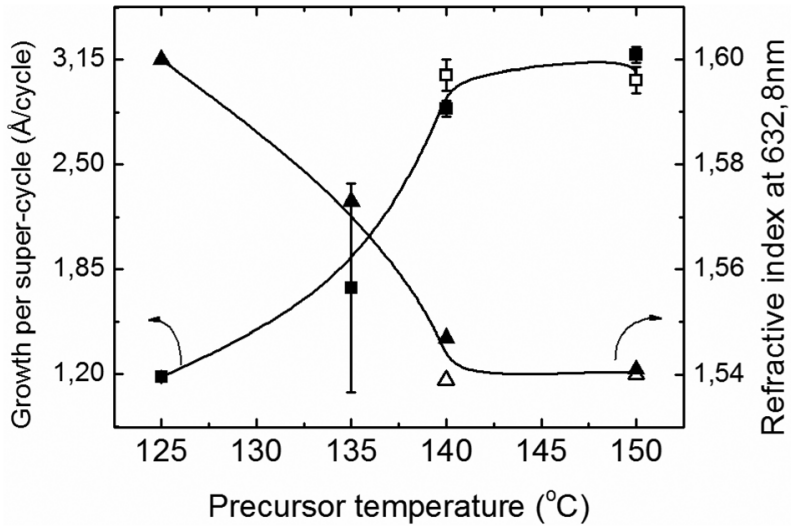

Fig. 4 Growth per cycle and refractive index of samples deposited using 200 super-cycles of $\mathrm{NaO}^{t} \mathrm{Bu}+\mathrm{H}_{2} \mathrm{O}+\mathrm{TMA}+\mathrm{H}_{2} \mathrm{O}$ on silicon at $250{ }^{\circ} \mathrm{C}$ with varying precursor temperature. The open and closed symbols represent depositions made with $0.5 \mathrm{~s}$ and $0.15 \mathrm{~s}$ pulses, respectively. 


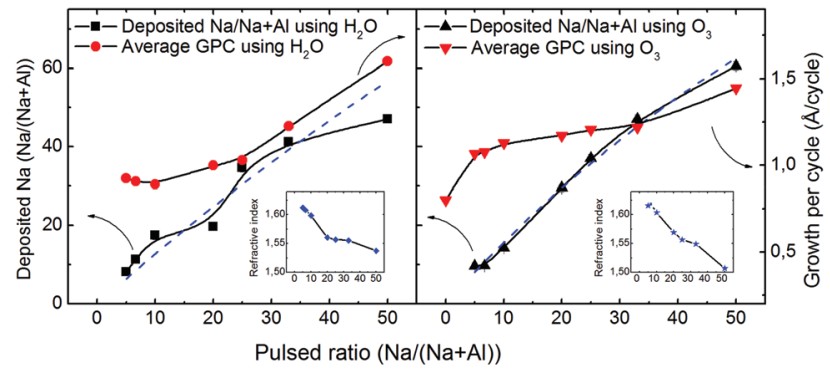

Fig. 5 Refractive index, growth rate and deposited composition using 500 total cycles on silicon at $250{ }^{\circ} \mathrm{C}$ with varying ratios of $\mathrm{NaO}^{t} \mathrm{Bu}$ and TMA with either $\mathrm{H}_{2} \mathrm{O}$ or $\mathrm{O}_{3}$ as oxygen source. The $\mathrm{NaO}^{t} \mathrm{Bu}$ was kept at $140{ }^{\circ} \mathrm{C}$ and $0.5 \mathrm{~s}$ pulses were used. The blue dashed line is the best fit of the surface utilization model.

sodium aluminate was also tested for large scale wafers and had a thickness variation of $c a .4 \%$ over an 8 " wafer.

In order to investigate the possibility of controlling the sodium content in the deposited films, a series of samples with varying ratio between $\left[\mathrm{NaO}^{t} \mathrm{Bu}+\mathrm{H}_{2} \mathrm{O}\right]$ and $\left[\mathrm{TMA}+\mathrm{H}_{2} \mathrm{O}\right]$ cycles were deposited, Fig. 5. A near linear relationship between pulsed and deposited composition was achieved for the aluminium rich compositions. The experiment was repeated using ozone as the oxygen source for both precursors, i.e. $\left[\mathrm{NaO}^{t} \mathrm{Bu}+\mathrm{O}_{3}\right]$ and $\left[\mathrm{TMA}+\mathrm{O}_{3}\right]$, Fig. 5 . The samples were prepared using a total of $c a$. 500 cycles of cationic precursor ensuring comparable samples. Pulsed sodium contents between $5-50 \%$ resulted in between 8 and 47 cat $\%$ of sodium relative to aluminium in the films when water was used as oxygen source or between 10 and 60 cat\% sodium relative to aluminium in the films when ozone was used. The refractive index varies quite systematically with composition, decreasing with increasing sodium content, as expected, and no significant difference between samples deposited using water or ozone.

The water based process do show some scattering in the dependency in pulsed to deposited compositions while the ozone based process appears to obey the surface utilization model as described by Nilsen et al. ${ }^{42}$ The best fits for the different systems are shown as blue dotted lines in Fig. 5. This suggests to the first approximation that the growth with water is governed by stability of hydroxyl groups on the surface, and that the ozone process is governed by the packing density of precursors on the surface. This assessment is further supported by the FTIR-analysis in Fig. 6, which shows that both the water and carbonate content for the samples deposited using the ozone based process is lower than the water based process. This may indicate that the water based processes contains a larger residue of hydroxyls which may more easily be converted into carbonates after deposition.

The samples deposited with high sodium content turned milky after reaction with the ambient in a matter of days to weeks; the samples with lower sodium contents were stable for at least eight months in air.

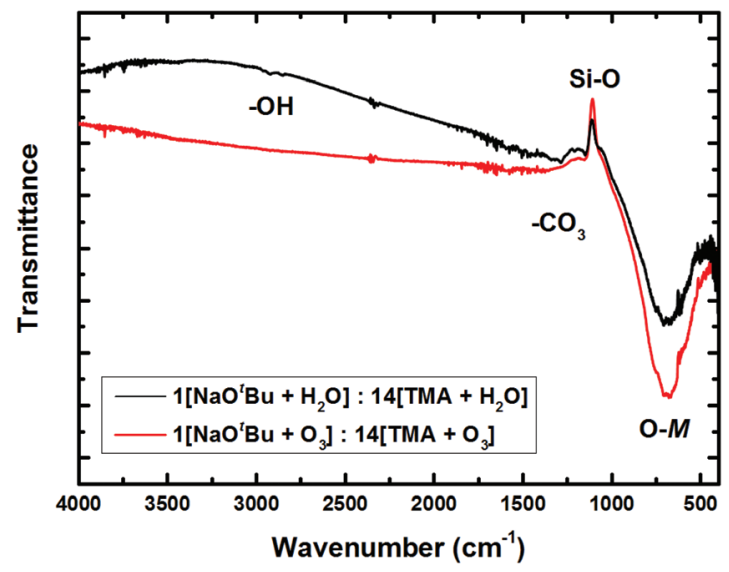

Fig. 6 Representative FTIR-spectra of samples deposited using a 1:14 ratio of sodium to aluminium using water or ozone as oxygen precursor. The black and red line show films deposited with water and ozone respectively.

Finally, the growth versus temperature was investigated in order to determine the ALD-window of formation of sodium aluminate from $\left[\mathrm{NaO}^{t} \mathrm{Bu}+\mathrm{H}_{2} \mathrm{O}\right]$ and [TMA $+\mathrm{H}_{2} \mathrm{O}$ ]. Depositions were carried out at temperatures from $225-375{ }^{\circ} \mathrm{C}$ with a rather constant film composition of $44.2 \pm 1.9$ cat $\% \mathrm{Na}$ for a $1: 1$ pulsing ratio, Fig. 7 . The samples were stable for weeks in air, apart for the sample deposited at $225{ }^{\circ} \mathrm{C}$ which was nonuniform and reacted in air within hours.

Although the film composition remains constant with deposition temperature, the growth per cycle is decreasing with temperature while the refractive index is increasing, Fig. 7 . These results can be interpreted by a reduction in density of hydroxyl group on the surface with increasing deposition temperature, as previously described for $\mathrm{TiCl}_{4}$ and TMA processes. ${ }^{43}$

In the current case the relative loss of $\mathrm{OH}$-groups appears to be constant for both the TMA-cycle and the $\mathrm{NaO}^{t} \mathrm{Bu}$ cycle, thus keeping the stoichiometry constant, decreasing the growth rate and increasing the refractive index due to reduction in amount of residual hydroxide groups or hydrogen in the films.

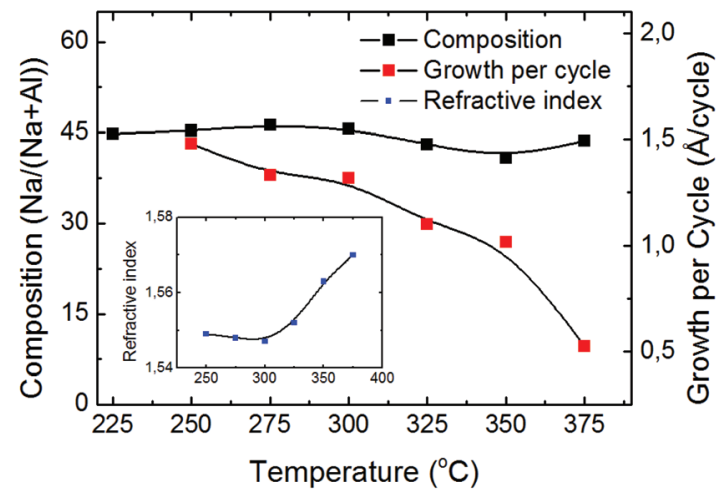

Fig. 7 Growth rate, refractive index and composition versus deposition temperature for samples deposited using 500 super-cycles of $\mathrm{NaO}{ }^{t} \mathrm{Bu}+$ $\mathrm{H}_{2} \mathrm{O}$ and TMA $+\mathrm{H}_{2} \mathrm{O}$ on silicon using $\mathrm{NaO}^{t} \mathrm{Bu}$ kept at $140{ }^{\circ} \mathrm{C}$ and pulsed for $0.5 \mathrm{~s}$. 


\section{Deposition of sodium containing thin films, the case of} NaTMSO

NaTMSO was used as precursor in combination with ozone with aim of depositing sodium silicate. The process was optimized by adjusting the precursor dose through changing the source temperature of NaTMSO. It proved impossible to obtain films without significant thickness gradients within the parameter-space explored, as shown in Fig. 8. The films were thickest at the precursor inlet and decreased in thickness almost linearly with the flow path through the reaction chamber. The evolution of the gradient was more or less independent of the precursor pulse length, precursor temperature, deposition temperature and ozone pulse length.

The [NaTMSO $+\mathrm{H}_{2} \mathrm{O}$ ] process was combined with the $\left[\mathrm{TMA}+\mathrm{H}_{2} \mathrm{O}\right]$ process with aim of formation of a sodium aluminate. This resulted in a reduction in thickness gradients, when compared to the sodium silicate process, to about $11 \%$ difference over an 8 " wafer.

Variations in the refractive index along with the thickness gradients were observed, typically varying from 1.490 to 1.454 on going from the precursor inlet to the exhaust. This span in index of refraction may indicate a variation in silicon content in the sodium silicate of 4-8 cat\% over the length of the substrate. ${ }^{44}$ This may indicate that a by-product of the reaction poisons the surface further downstream, leading to a reduction in growth rate. In order to ensure that the thickness and refractive index gradients are not due to a reactor specific feature, depositions of sodium silicate were tested in an ASM F-120 Sat reactor at $250{ }^{\circ} \mathrm{C}$ with two different pulse lengths at 150 and $350{ }^{\circ} \mathrm{C}$ with similar results and without significant variations between the deposition temperature.

\section{Deposition of potassium containing thin films}

Aluminates of potassium was deposited using combinations of the $\left[\mathrm{KO}^{t} \mathrm{Bu}+\mathrm{H}_{2} \mathrm{O}\right]$ and $\left[\mathrm{TMA}+\mathrm{H}_{2} \mathrm{O}\right]$ processes in a similar manner as for formation of aluminates using $\mathrm{NaO}^{t} \mathrm{Bu}$. In the first experiments, a 1:1 ratio between $\left[\mathrm{KO}^{t} \mathrm{Bu}+\mathrm{H}_{2} \mathrm{O}\right]$ and $\left[\mathrm{TMA}+\mathrm{H}_{2} \mathrm{O}\right]$ was used. The precursor dose of $\mathrm{KO}^{t} \mathrm{Bu}$ was con-

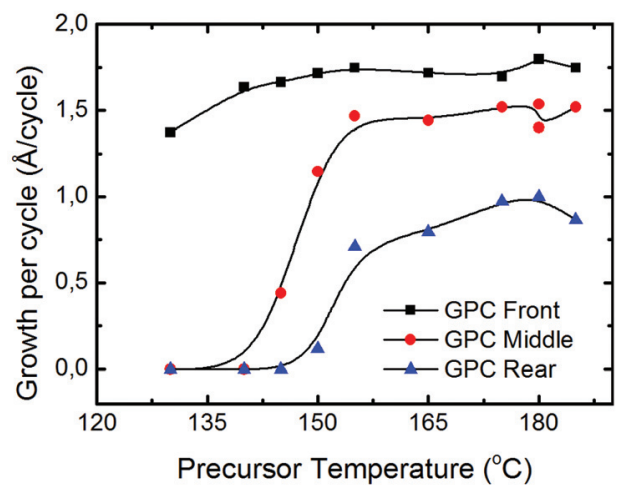

Fig. 8 Growth per cycle of $\mathrm{Na}-\mathrm{Si}-\mathrm{O}$ on silicon at $250{ }^{\circ} \mathrm{C}$ using 500 cycles of $0.5 \mathrm{~s}$ pulses of NaTMSO and $2 \mathrm{~s}$ ozone pulse and varying NaTMSO temperature at different positions in the 8 " reactor chamber along the flow direction.

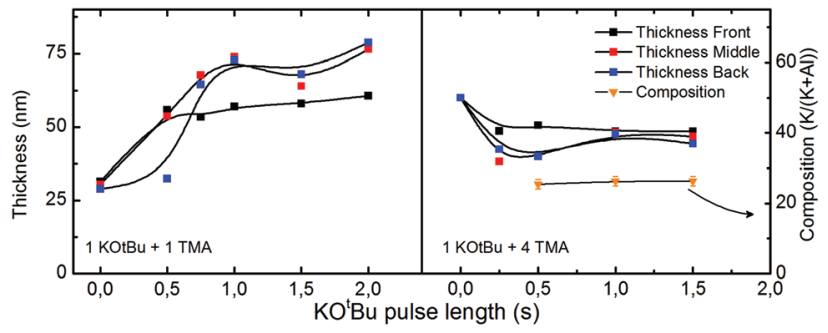

Fig. 9 Thickness and composition of samples deposited with a total 500 cycles with a 1 to 1 ratio, or a 1 to 4 ratio of $\mathrm{KO}^{t} \mathrm{Bu}+\mathrm{H}_{2} \mathrm{O}$ and TMA $+\mathrm{H}_{2} \mathrm{O}$ cycles with varying $\mathrm{KO}^{t} \mathrm{Bu}$ pulse length deposited at $250{ }^{\circ} \mathrm{C}$ and a precursor temperature of $170{ }^{\circ} \mathrm{C}$.

trolled by increasing the precursor temperature or the pulse duration. However, independent of the dose, the films had significant thickness gradients, as shown in the left part of Fig. 9. It appeared that the area closest to the precursor inlet showed saturative growth with no thickness gradients, however further downstream, the samples were thicker even though there were no signs of thermal decomposition. It was therefore suspected that the ratio of potassium to aluminium in the films was too high resulting in a hygroscopic film provoking uncontrolled growth through a reservoir effect. The pulsed composition was therefore changed to a ratio of $1: 4$ between $\left[\mathrm{KO}{ }^{t} \mathrm{Bu}+\mathrm{H}_{2} \mathrm{O}\right.$ ] and [TMA $+\mathrm{H}_{2} \mathrm{O}$ ]. By increasing the precursor pulse length, ALD-growth with a consistent composition was achieved throughout the 8 " reaction chamber, as shown in Fig. 9. For further studies, the pulse length of $\mathrm{KO}^{t} \mathrm{Bu}$ was set to $1 \mathrm{~s}$ at a sublimation temperature of $170^{\circ} \mathrm{C}$.

The ability to control the deposited composition was explored by depositing different ratios of $\left[\mathrm{KO}^{t} \mathrm{Bu}+\mathrm{H}_{2} \mathrm{O}\right]$ and [TMA $\left.+\mathrm{H}_{2} \mathrm{O}\right]$ cycles, Fig. 10. The growth behaviour of this system differs from the $\mathrm{NaO}^{t} \mathrm{Bu}$ system, although the ligand and the molecular structures of the precursors are similar. The growth per cycle is lower for intermediate ratios of potassium pulses in contrast to sodium containing samples. The composition seems to saturate near 28 cat\% potassium in the films

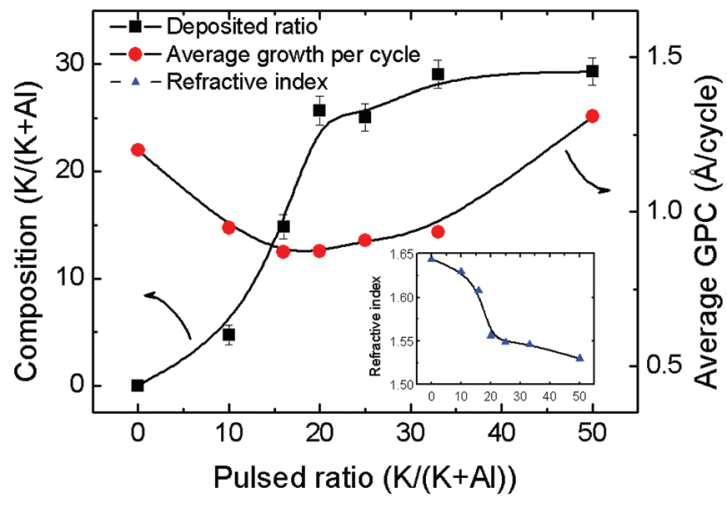

Fig. 10 Refractive index and deposited composition using 500 total cycles on silicon at $250{ }^{\circ} \mathrm{C}$ with varying ratios of $\mathrm{KO}^{t} \mathrm{Bu}$ and TMA with $\mathrm{H}_{2} \mathrm{O}$ oxygen source. The $\mathrm{KO}^{t} \mathrm{Bu}$ was kept at $170^{\circ} \mathrm{C}$ and using $1 \mathrm{~s}$ pulses. 


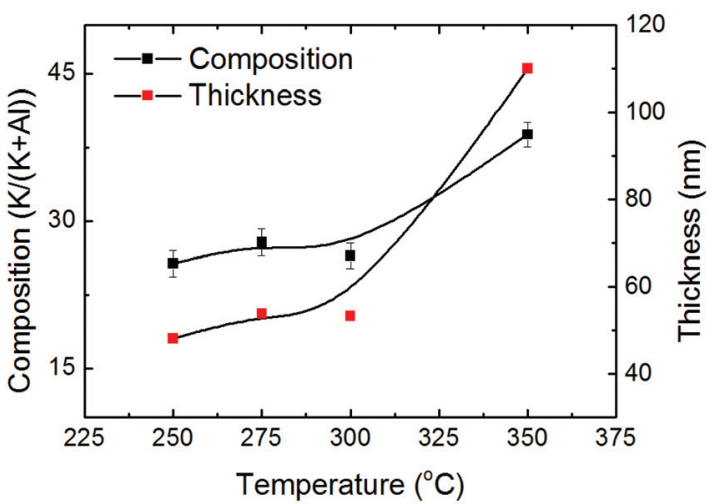

Fig. 11 Growth per cycle and composition of samples deposited using 100 super cycles consisting of 1 cycle $\mathrm{KO}^{t} \mathrm{Bu}$ and water and 4 cycles of TMA and water deposited at various temperatures. $\mathrm{KO}^{t} \mathrm{Bu}$ was kept at $170{ }^{\circ} \mathrm{C}$ and pulsed for $1 \mathrm{~s}$. Thickness for the sample deposited at $350^{\circ} \mathrm{C}$ was estimated from XRF-measurements.

for pulsing composition above $20 \%$ pulsed potassium. X-ray diffraction analysis of these films proves an amorphous structure regardless of the composition. The growth rate and composition as a function of temperature was investigated to establish a working range for the system. Growth per cycle was observed similar for temperatures between 250 and $300{ }^{\circ} \mathrm{C}$, whereas a sudden increment in the growth was observed at higher temperatures believed to be a result of precursor decomposition, Fig. 11.

FTIR-analysis was used to determine presence of carbonates or hydroxides in the deposited films. The major features in the FTIR-spectra of these samples were the characteristic bands of carbonate for the films with high potassium content as shown in Fig. 12, even though water was used as oxygen source. This may, in the same manner as for the sodium equivalent, stem from remains of hydroxides in the films which convert into carbonates upon exposure to air.

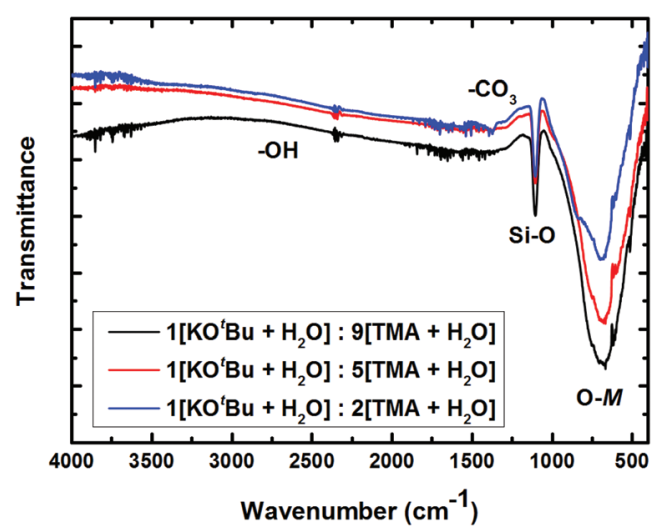

Fig. 12 Representative FTIR-spectrum of samples deposited using 1:2, $1: 5$ and $1: 9$ ratios of potassium to aluminium using water as oxygen precursor.

\section{Conclusions}

Six different precursor candidates for deposition of sodium and potassium containing thin films with atomic layer deposition have been evaluated. $\mathrm{NaO}^{t} \mathrm{Bu}$ and $\mathrm{KO}^{t} \mathrm{Bu}$ have been shown to give films with controllable stoichiometry in both $\mathrm{Na}-\mathrm{Al}-\mathrm{O}$ and $\mathrm{K}-\mathrm{Al}-\mathrm{O}$ systems using both water and ozone or water, respectively. The sodium and potassium tert-butoxides have ALD-windows from 225 to at least $375{ }^{\circ} \mathrm{C}$ and 250 to $300{ }^{\circ} \mathrm{C}$, respectively.

The structure of sodium tert-butoxide is reported as a hexamer with highly distorted tert-butyl groups.

This work enables deposition of sodium and potassium containing thin films using ALD, opening for study of a range of compounds that have previously been unavailable.

\section{Acknowledgements}

The authors would like to acknowledge the Department of Geology at the University of Oslo for use of and support with $\mathrm{XRF}$ instrumentation. The research leading to these results received funding from the Research Council of Norway (Project 200030).

\section{Notes and references}

1 V. Miikkulainen, M. Leskelä, M. Ritala and R. L. Puurunen, J. Appl. Phys., 2013, 113, 021301.

2 O. Nilsen, V. Miikkulainen, K. B. Gandrud, E. Østreng, A. Ruud and H. Fjellvåg, Phys. Status Solidi A, 2014, 211, 357-367.

3 M. Putkonen, T. Aaltonen, M. Alnes, T. Sajavaara, O. Nilsen and H. Fjellvag, J. Mater. Chem., 2009, 19, 8767-8771.

4 E. Østreng, P. Vajeeston, O. Nilsen and H. Fjellvåg, RSC Adv., 2012, 2, 6315-6322.

5 T. Aaltonen, O. Nilsen, A. Magrasó and H. Fjellvåg, Chem. Mater., 2011, 23, 4669-4675.

6 T. Aaltonen, M. Alnes, O. Nilsen, L. Costelle and H. Fjellvag, J. Mater. Chem., 2010, 20, 2877-2881.

7 M. E. Donders, H. C. Knoops, W. M. M. Kessels and P. H. Notten, ECS Trans., 2011, 41, 321-330.

8 V. Miikkulainen, O. Nilsen, M. Laitinen, T. Sajavaara and H. Fjellvag, RSC Adv., 2013, 3, 7537-7542.

9 V. Miikkulainen, A. Ruud, E. Østreng, O. Nilsen, M. Laitinen, T. Sajavaara and H. Fjellvåg, J. Phys. Chem. C, 2013, 118, 1258-1268.

10 J. Hämäläinen, J. Holopainen, F. Munnik, T. Hatanpää, M. Heikkilä, M. Ritala and M. Leskelä, J. Electrochem. Soc., 2012, 159, A259-A263.

11 J. Hämäläinen, F. Munnik, T. Hatanpää, J. Holopainen, M. Ritala and M. Leskelä, J. Vac. Sci. Technol., A, 2012, 30, 01A106.

12 E. Østreng, H. H. Sønsteby, T. Sajavaara, O. Nilsen and H. Fjellvåg, J. Mater. Chem. C, 2013, 1, 4283-4290. 
13 P. Brinks, H. Heijmerikx, T. A. Hendriks, G. Rijnders and M. Huijben, RSC Adv., 2012, 2, 6023-6027.

14 J. Y. Son, Y. H. Shin and C. S. Park, J. Appl. Phys., 2008, 104, 033538.

15 A. Duk, M. Schmidbauer and J. Schwarzkopf, Appl. Phys. Lett., 2013, 102, 091903.

16 J. Schwarzkopf, M. Schmidbauer, T. Remmele, A. Duk, A. Kwasniewski, S. Bin Anooz, A. Devi and R. Fornari, J. Appl. Crystallogr., 2012, 45, 1015-1023.

17 M. Blomqvist, J.-H. Koh, S. Khartsev, A. Grishin and J. Andreasson, Appl. Phys. Lett., 2002, 81, 337-339.

18 D. Kim, E. Lee, M. Slater, W. Lu, S. Rood and C. S. Johnson, Electrochem. Commun., 2012, 18, 66-69.

19 M. D. Slater, D. Kim, E. Lee and C. S. Johnson, Adv. Funct. Mater., 2013, 23, 947-958.

20 N. Janne and T. Marina, J. Phys.: Condens. Matter, 2012, 24, 325901.

21 C.-R. Cho and B.-M. Moon, Integrated Ferroelectrics, 2002, 45, 39-48.

22 J. Schwarzkopf, M. Schmidbauer, A. Duk, A. Kwasniewski, S. B. Anooz, G. Wagner, A. Devi and R. Fornari, Thin Solid Films, 2011, 520, 239-244.

23 R. Kužel and J. Buršík, Thin Solid Films, 2013, 530, 2-8.

24 Š. Kunej, A. Veber and D. Suvorov, J. Am. Ceram. Soc., 2013, 96, 442-446.

25 K.-i. Katsumata, C. E. J. Cordonier, T. Shichi and A. Fujishima, J. Am. Chem. Soc., 2009, 131, 3856-3857.

26 D. Tsymbarenko, I. Korsakov, A. Mankevich, G. Girichev, E. Pelevina and A. Kaul, ECS Trans., 2009, 25, 633-638.

27 B. M. Nichols, B. H. Hoerman, J.-H. Hwang, T. O. Mason and B. W. Wessels, J. Mater. Res., 2003, 18, 106-110.
28 M. V. Romanov, I. E. Korsakov, A. R. Kaul, S. Y. Stefanovich, I. A. Bolshakov and G. Wahl, Chem. Vap. Deposition, 2004, 10, 318-324.

29 A. Onoe, Y. Tasaki and K. Chikuma, J. Cryst. Growth, 2005, 277, 546-554.

30 P. Chin Goh, K. Yao and Z. Chen, Appl. Phys. Lett., 2011, 99, 092902.

31 U. Wannagat, in Pure Appl. Chem., 1969, vol. 19, p. 329.

32 T. Fjeldberg, M. F. Lappert and A. J. Thorne, J. Mol. Struct., 1984, 125, 265-275.

33 R. Grüning and J. L. Atwood, J. Organomet. Chem., 1977, 137, 101-111.

34 J. C. Green, M. Payne, E. A. Seddon and R. A. Andersen, J. Chem. Soc., Dalton Trans., 1982, 887-892.

35 K. F. Tesh, T. P. Hanusa and J. C. Huffman, Inorg. Chem., 1990, 29, 1584-1586.

36 E. Weiss, K. Hoffmann and H.-F. Grützmacher, Chem. Ber., 1970, 103, 1190-1197.

37 T. Greiser and E. Weiss, Chem. Ber., 1977, 110, 3388-3396.

38 M. H. Chisholm, S. R. Drake, A. A. Naiini and W. E. Streib, Polyhedron, 1991, 10, 337-345.

39 D. J. Comstock and J. W. Elam, J. Phys. Chem. C, 2012, 117, 1677-1683.

40 G. Sheldrick, Acta Crystallogr., Sect. A: Fundam. Crystallogr., 2008, 64, 112-122.

41 C. B. Hubschle, G. M. Sheldrick and B. Dittrich, J. Appl. Crystallogr., 2011, 44, 1281-1284.

42 O. Nilsen, E. Rauwel, H. Fjellvag and A. Kjekshus, J. Mater. Chem., 2007, 17, 1466-1475.

43 R. Matero, A. Rahtu, M. Ritala, M. Leskela and T. Sajavaara, Thin Solid Films, 2000, 368, 1-7.

44 H. Doweidar, J. Non-Cryst. Solids, 2002, 303, 387-392. 